
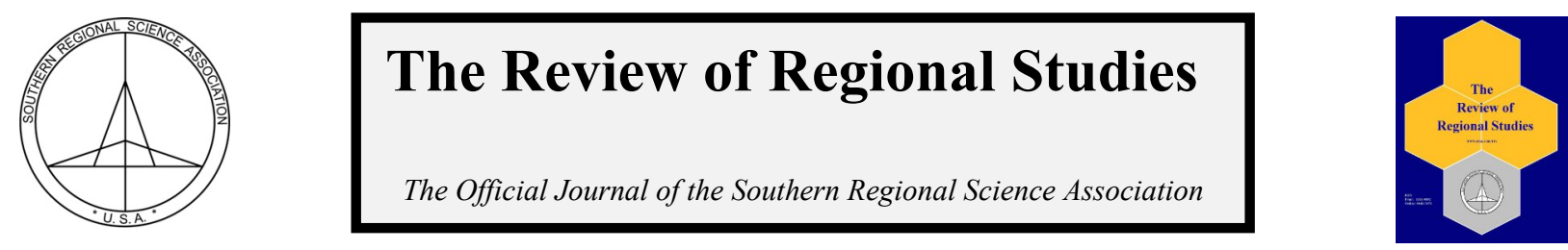

\title{
Exploring Patterns in ICT Growth and Development in Africa: A Kohonen Map Analysis
}

\author{
Olumayokun Soremekun ${ }^{\mathrm{a}}$, and Charles A. Malgwi ${ }^{\mathrm{b}}$ \\ ${ }^{a}$ Department of Mathematical Sciences, Bentley University, USA \\ ${ }^{b}$ Department of Accountancy, Bentley University, USA
}

\begin{abstract}
This paper explores whether the adoption and use of mobile phones in Africa following the United Nations Millennium Development Goal \#8 is seminal relative to other Information and Communication Technologies (ICTs). The dataset consists of the number of Internet users, computer users, and mobile subscribers per 100 people. We use Kohonen Self Organizing Maps on a panel of 48 countries organized in four geographic regions and two cohorts over the 2001-2007 period. Results show the existence of a digital divide in Africa overall, with northern and southern countries making significant progress while the western and eastern regions lag behind. Keywords: information communication technology; Africa, digital divide, Kohonen map
\end{abstract}

JEL Codes: O55, O30, R12

\section{INTRODUCTION}

In the last decade, Africa has witnessed a dramatic increase in the adoption and use of Information and Communication Technologies (ICTs). This increase is in line with Goal 8 of the United Nations (UN) Millennium Development Goals (MDGs), which calls for cooperation with the private sector, to make available the benefits of new technologies, especially ICTs. On average, the number of mobile telephone subscribers in Africa is six times more than the number of Internet users and twelve times more than fixed telephone users. In the broad field of information and communication technologies (ICT), telecommunications and computing are among the most prominent technological infrastructures. Such infrastructures comprise the Internet, telephones (both land and wireless), personal computers (PCs), and power supply (Oyelaran-Oyeyinka and Adeya, 2004; Kim, Lee, Lee and Choi, 2004). Several studies on ICT have continued to point to the direction of the widening digital divide among many countries (Chen and Wellman, 2007; Ho and Tseng, 2006; Deichmann et al., 2006).

The concept of digital divide has been viewed differently by many scholars. For example, Mazrui and Mazrui (2001) refer to it as the differences in economic opportunity, while at the same time acknowledging the salient effects of culture, religious doctrine, and gender with technological changes. Inversely, Giddens (2000), however, views technology as the main driver to economy, politics, and culture, because these variables are largely influenced by the development of systems of communication. Most researchers consider ICT to be an umbrella term, which refers to a wide range of devices, from computers, telephony, facsimile, and

Soremekun is a Ph.D. student in the Department of Mathematical Sciences, Bentley University, Waltham, MA. Malgwi is a Professor of Accounting in the Department of Accountancy, Bentley University, Waltham, MA. Corresponding Author: C..A. Malgwi E-mail: cmalgwi@bentley.edu

C) Southern Regional Science Association 2014.

ISSN 1553-0892, 0048-749X (online)

www.srsa.org/rrs 
televisions, to cellular phones and software applications that facilitate the transmission of voice, data, video, and text. For the purpose of this study, ICT indicators include the access and application of mobile phone technologies, personal computers, and Internet subscriptions in Africa.

This study uses Kohonen Self-Organizing Maps (Kohonen 1982; 1995; Kohonen et al. 1996) to explore patterns in ICT growth and development and to discover other economic and social measures that evolve in tandem with digital development in Africa following the declaration of the United Nations Millennium Development Goal number 8. The scope of this study covers a seven year period from 2001 to 2007, both years inclusive. We focus on this time period because it allows us to evaluate the extent to which ICT has evolved post the MDG declaration, midway to the goal; second, data were relatively available for all seven years up to 2007.

In an attempt to address this main research question, the following associated questions are explored. First, to explore if a digital disparity exists within Africa and second, to identify the natural groups of countries as positioned on the Kohonen map. This enables us to investigate patterns of ICT growth and development in Africa relative to certain economic and social measures.

African economies may still be far from closing the gap in these three dimensions of ICT (Sachs, 2007; Asiedu, 2006; Bessler, 2003). In the case of the Internet, Roycroft and Anantho (2003) found that African nations face two challenges with regards to the digital divide-lack of basic infrastructure for Internet access and low Internet subscription due to high access costs for those who have the potential for access. The absence of good connectivity infrastructure translates into lack of affordable access to ICT such as the Internet connections, PCs, and telephones. For example, Rao (2001) documented the wide disparities of cost, access, and use of Internet adoption that exist within and between African countries due to a variety of issues such as regulatory factors, tariff structures, level of technological development, educational levels, and socio-economic differences.

The widening gap of ICT in many developing economies has been a major concern to many organizations. For example, the United Nations (UN) has been in the forefront in promoting ICT availability and use. Goal number 8 of the UN's MDGs of 2000 specifically calls for cooperation with the private sectors to make available the benefits of new technologies, especially in ICTs (UN Department of Economic and Social Affairs, 2008). Consistent with the UN's vision, many studies have linked and identified the importance of ICT as a powerful tool that drives economic and social forces (The World Bank, 2001; Kumar and Zahn 2003). Reforms from many African governments which allowed for the privatization of telecommunications sectors and allowed for liberal markets have encouraged a dramatic growth and development of ICT, especially in telecommunications in Africa. For example, similar to South Africa, most Sub-Saharan African governments have adopted the GSM system (Global System for Mobile Communications), and many of the East and Central African countries are doing the same (LaFraniere, 2005; Jensen, 2002).

GSM is the most widely adopted mobile standard in the world. It supplies a broad range of technology and has met a growing demand for reduced cost in hardware solutions for mobile network operators worldwide. It has built a track record in managed services through a focus on delivery excellence and cost reduction in the network maintenance process. GSM is the system 
that is typically found in African countries mainly because of its low cost and relative ease of use and service (LaFraniere, 2005; Jensen, 2002).

A major goal of this paper is to first, explore if a digital divide exists within the African continent and second, identify the patterns of ICT development within Africa as well as other patterns of economic or social development that might occur in tandem. The remainder of the paper is organized as follows: The second section explores the empirical evidence of growth and development in ICT in Africa. Section three discusses the Kohonen SOM methodology used in this study. Section four and five present the results and conclusions, respectively.

Our paper differs from that of Deichmann et al. (2006) in a number of ways. First is the scope of study. They specifically recommended an extension of similar studies with availability of more years of data to investigate the potential convergence of countries to particular patterns of digital development. Their exploratory study covered only a three-year period (2001-2003), including 45 African countries. Our study includes 48 African countries and 15 indicator variables over a seven-year period (2001-2007).

Second, we expanded Deichmann et al. (2006) by including the third variable - mobile subscribers, as it is one of the three indicator variables adopted by the UN MDGs, specifically goal number 8 which is related to ICT diffusion. This allowed us to be one of the first to examine a longitudinal assessment of the UN's MDG goal 8 using SOM to explore the pattern of ICT growth and development in 48 African countries in tandem with economic and social measures.

Third, methodologically, we consider two Kohonen maps in our analysis, one for 2001 and the other for 2007. This allowed us to examine ICT diffusion in Africa as it stood in 2001 and also separately examine the concept of ICT diffusion in 2007. We were thus able to compare and contrast results for both years as well as consider the contextual implications of both maps. This approach also helped to ensure readability of the graphs, as country positions at the beginning of our time period (2001) and at the end of our time period (2007) were better highlighted on two separate maps. Compressing them together on one map would have made it harder to analyze and interpret.

Finally, while their countries of interest consist of all countries with available data (160, including 45 African), our study is innovative as we focused exclusively on Africa by considering all 48 African countries with available data. This allowed us to examine ICT diffusion solely from the African perspective and to highlight disparities and similarities in ICT diffusion that are exclusive to Africa.

\section{INFORMATION AND COMMUNICATION TECHNOLOGY IN AFRICA}

One notable area of growth in African economies is in telecommunications and ICTs. There is empirical evidence of exponential ICT growth and development in Africa during the years 2001-2007, especially in the subscription of wireless mobile technologies. A news article in the New York Times by LaFraniere (2005) on mobile phone technology in the African market indicates that Africa is the world's fastest-growing cell phone market. The number of mobile subscribers jumped from 7.5 million in 1999 to 76.8 million in 2004, an average annual increase of 58 percent. By early 2008, Africa surpassed North America in terms of mobile subscribers, with more than 280 million (www.wirelessfederation.com/news/, May, 2008).

The old method of communication which involved writing and sending letters by post and traveling for days, with attendant costs on time and money, has now been supplanted by 
instant messaging. That is, there is a transformation of technology from the legacy system of slow communication to real-time messaging. A study noted that subscribers in Nigeria, Africa's most populous country, grew from about 4 million in 2003 to about 113 million in 2008 (Industry Statistics, 2008, http:/www.ncc.gov.ng/subscriberdata.htm). The relative low cost of cell phones, subscriptions, and cost per minute makes mobile phones more affordable compared to the higher costs of PCs and Internet service.

A major factor impeding Internet adoption and use in Africa is the lack of a strong, dedicated backbone of networks. According to Telcordia (http://www.telcordia.com), Internet "host" computers are a critical aspect of the Internet infrastructure. The interconnection of networks is more difficult because of extensive backhauling of traffic from interconnection points located elsewhere in the developed world (Roycroft and Anantho, 2003). The vast majority of all global Internet hosts are located physically in North America. For example, in the US, you have approximately 2.4 persons per Internet host whereas in Africa the number of Internet hosts is a small fraction with approximately 3,700 persons per Internet host.

Tyler and Gopal (2010) noted in their study of access to telephones and cell phones in Sub-Saharan Africa that SOM is a useful tool for determining continental or regional patterns and clusters in development. The SOM tool has the advantage over other methods of cluster analysis of better visualization, and its monotonic property allows us to see how these patterns vary across the map. Hua, Skaletsky and Westermann (2009) also utilized SOM to evaluate the Central Intelligence Agency (CIA) World Factbook data and to identify the existence of any patterns among selected countries vis-à-vis their people, economies, communications, and defense forces. Similarly, Nguyen, Haighton, and Hudson (2008) and Deichmann et al. (2007) used SOM to evaluate the levels of living standards among Vietnamese provinces, and the relative evolution and determinants of international digital divide, respectively. Consistent with similar studies, this paper utilizes the SOM technique in the analysis of our data. This study will be of interest to the UN MDGs in assessing growth and development (or lack thereof) in relation to the declaration made by the UN towards providing technological development to African economies.

\section{METHODOLOGY}

Using Kohonen Self-Organizing Maps (SOM), this paper explores the patterns of ICT growth and development in Africa since the UN declaration of the MDGs in 2000. Specifically, the paper investigates patterns in the growth and development of ICT in Africa attempting to identify other economic, infrastructural, and social measures (Table 1) that evolve in tandem with digital development in Africa. An SOM (a special case of neural networks) is an exploratory data analysis technique where multi-dimensional data is projected onto a two dimensional space to allow for clear visualization of the data and easy identification of groups with similar characteristics. The choice of a two dimensional space here gives us the best visualization of results as a three dimensional space or a one dimensional space would not allow us to see the results as clearly. Variables representing the ICT and economic measures in a country evolve in a monotonic manner as one moves across the Kohonen map. The monotonic movement makes it possible to identify countries that are similar in ICT, economic and social measures. While several studies have utilized SOM, its application to evaluate data on ICT growth and development in African economies is limited.

(c) Southern Regional Science Association 2014. 
Table 1: Indicators Used in the Study of the Digital Divide in Africa

\begin{tabular}{|l||l|l|l|l|l|}
\hline Group & Indicator & Description & Year(s) & Source \\
\hline Digital Development & Computers & Computers per 100 people & $2001-2007$ & World Bank \\
\hline Digital Development & Internet & Internet users per 100 people & $2001-2007$ & World Bank \\
\hline Digital Development & Mobile & Mobile subscribers per 100 people & $2001-2007$ & World Bank \\
\hline Economic & Income & GNI per capita in international ppp (\$) & $2001-2007$ & World Bank \\
\hline Economic & Gini & Average Gini index for reported years & $2001-2007$ & World Bank \\
\hline Economic & Trade & Trade in goods as a \% of GDP & $2001-2007$ & World Bank \\
\hline Infrastructure & Maintel & Main telephone lines per 100 & $2001-2007$ & World Bank \\
\hline Infrastructure & Costcall & Cost of three-minute local call (\$PPP) & $2001-2007$ & ITU \\
\hline Infrastructure & Electric & Electricity consumption kwh/capita & $2001-2007$ & World Bank \\
\hline Demographic & Pl564 & \% of population age 15-64 & $2001-2007$ & World Bank \\
\hline Demographic & P65plus & $\%$ of population 65 and older & $2001-2007$ & World Bank \\
\hline Demographic & PSchool & Primary School Enrollment & $2001-2007$ & World Bank \\
\hline Demographic & SSchool & Secondary School Enrollment & $2001-2007$ & World Bank \\
\hline Demographic & Urban & Urban population as a \% of total & $2001-2007$ & World Bank \\
\hline Risk & Risk & Country risk rating & $1999-2009$ & IHS Global \\
\hline
\end{tabular}

${ }^{\mathrm{a}}$ International Telecommunication Union

There has been a demonstration of a growing body of work suggesting the usefulness and relevance of SOM in regional studies. For example, Arribas-Bel, Nijkamp, and Scholten (2011) employed SOM algorithm in studying key dimensions of the urban sprawl phenomenon in Europe. The study investigated how the different dimensions interact with each other and their associated behavior. They revealed interesting results and pointed out that their results could not have been nicely unveiled otherwise. Similarly, Kauko (2004) applied the SOM technique to identify housing sub-markets within Amsterdam, The Netherlands in an urban setting. The study, using SOM, was able to identify that price alone was an insufficient criterion when compared with another urban housing market—namely, Helsinki, Finland.

The study of networks and spatial economics has also been well researched utilizing SOM in Yan and Thill (2009) and Kulkarni et al. (2002). Both studies acknowledged the robustness in the application of this model. Unlike other models used in regional studies, which rely heavily on conventional economic theory, this approach allows for increasing returns, multiple equilibria, 'satisficing' behavior, imperfect information, and stochasticity (Kulkarni et al. 2002). Also, the SOM model could be used to explore spatio-temporal dynamics under different assumptions relating to industrial composition, inter-industry linkages, and the spatial juxtaposition of firms (industries). Spatial economic studies on African geographic regions have lacked the application of the SOM methodology. This paper thus attempts to fill that gap by 
employing the SOM algorithm on data from 48 African countries covering a period of seven years (2001-2007) to address the question of just how much ICT has evolved over this time period and the associated patterns in economic, social, and cultural factors.

Deichmann et al. (2007) and Hua, Skaletsky, and Westermann (2009) pointed out in their studies that Kohonen maps can be compared to a factor analysis followed by a cluster analysis and are a very effective tool for clustering data. Unlike the SOM property, factor-cluster analyses do not allow for clear visualization of results. The results of our SOM are depicted in the form of a hexagonal lattice using the SOM Toolbox in MATLAB. An SOM (a special case of a neural network) consists of neurons organized on a regular low-dimensional grid (Larose, 2005). Each neuron is a d-dimensional weight vector where $d$ is equal to the dimension of the input vectors (input variables). The neighborhood relation between the neurons dictates the topology or structure of the map. Topology consists of two factors - a local lattice structure which can be rectangular or hexagonal and a global map shape which can be a sheet, cylinder or toroid (Vesanto et al., 2000).

Two main outputs are generated by the Kohonen algorithm. The first output is the Umatrix (Figure 1). This shows the relative positions of countries on the map, based on the similarities in the indicator values for each country. The second output is the individual component maps (Figures 2 and 3). The component maps show the estimated values of each variable at each position on the map. For example, the component map for the 'mobile subscribers per 100 people' variable shows that the countries with the highest concentration are located in the top right corner of the map (shown in the deep red colors) and the concentration decreases when moving towards the bottom. The high concentration is reflected by the red colors while the blue colors indicate low concentrations.

A major advantage of Kohonen maps is the self-organizing property of the map which makes estimated components vary in a monotonic way across the map (Deichmann et al. 2007). This allows us to easily identify the characteristics of each cluster on the map; for example, moving from the bottom to the top of the map implies an improvement in digital development. Thorough introductions and discussions of this methodology and case studies can be found in a variety of papers (Kaski and Kohonen 1995, Kohonen 2001, Deichmann et al. 2007, Hua, Skaletsky, and Westermann 2009).

A variety of packages are available to construct Kohonen maps, but, for the purpose of our analysis, we use the MATLAB and the SOM Matlab toolkit, which can be downloaded at no cost from the website http://www.cis.hut.fi/projects/somtoolbox/. Following Deichmann et al. (2007) and Hua, Skaletsky, and Westermann(2009), we choose Matlab because it is one of the more powerful SOM packages that produce clear and easy-to-understand graphs. The SOM Toolbox uses the function SOM_TOPOL_STRUCT and SOM_MAKE to determine the size of the output map. The first step in estimating the size of the map is to determine the number of map units by using the SOM_TOPOL_STRUCT function in the SOM Toolbox. Basically, the two biggest eigenvalues of the correlation matrix are calculated and the ratio between side lengths of the map grid is set to the square root of this ratio. The actual side lengths are then set so that their product is as close to the desired number of map units as possible. After this, the map size is determined. If the lattice of the grid is hexagonal, the ratio is modified a bit to take it into account. If the lattice is hexagonal and shape is toroid, the map size along the first axis must be even. Typically a 'big' map has four times the default number of map units and a 'small' map has 0.25 times the default number of map units (SOM Toolbox 2.0 documentation, 2003). 
This study is not free from limitations. We encountered difficulty in getting data for the time period $(2001-2007)$ under consideration in some countries and therefore had to apply imputation using the multiple imputation models in PASW Statistics 17 to replace missing values. Further, we limited our sample of developing countries to that of Africa only. Future studies could consider including other developing countries in South America and Asia. Finally, our study only considered one of the eight goals of the UN MDGs. Future studies may examine the level of growth or progress of other UN Millennium Development Goals.

\subsection{Algorithm}

Following the method described in the previous section, the algorithm selects a map with four columns and nine rows, thus creating a map with 36 positions. A random 15 dimensional vector (number of dimensions corresponds to the number of variables) is then assigned to each of the 36 positions. This is an iterative process, and in the first iteration, the first country with its 15 dimensional vector is considered, and the Euclidean distance between the data vector for that country and each other random vectors is computed. A best matching unit (BMU) is identified as the map position for which the Euclidean distance is smallest. After the identification of the BMU, the random vector and neighbors at that position are modified so as to come closer to the actual data vector of that country.

The next iteration looks at another country and performs the same calculations. Through successive iterations, the BMUs and their modified vectors change at a lower rate leading to stabilization and convergence. At the end, the algorithm has computed a set of 36 estimated vectors where one is for each map position. Each country is positioned on the map on the basis of the smallest Euclidean distance between its data vector and each of the 36 estimated vectors obtained at the end of the Kohonen algorithm described above. It is important to note here that the positioning of countries on the map is not based on geography but on the Euclidean distance between the estimated vectors. This is not to say that countries in the same region cannot be clustered together on the Kohonen map. It is in fact quite possible because countries in the same geographical region would probably have indicator values that are quite similar. Detailed discussions of the Kohonen network algorithm can be found in Kaski and Kohonen (1995), Kohonen (2001), and, most recently, Deichmann et al. (2007) and Hua, Skaletsky, and Westermann (2009).

\subsection{Dataset}

The indicators included in the analysis are guided by the choice of variables in Chinn and Fairlie (2007) and Deichmann et al. (2007). Our final analysis included 48 African countries and 15 indicator variables over the years 2001-2007. These years are the most recent for which comprehensive data is available. A full list of countries and corresponding three-digit international codes are included in Appendix A. The variables in the dataset are arranged into the following five groups as shown in Table 1: Digital Development, Economic, Infrastructure, Demographic and Risk. These groupings are commonly agreed-upon factors for explaining the differences across regions in digital growth (Deichmann et al. 2007). The digital development group includes three indicators which are used to measure digital divide. These are the number of Internet users per 100 people, number of computers per 100 inhabitants, and the number of mobile subscribers per 100 people. We expand the work of Deichmann et al. (2007) by including the third variable - mobile subscribers, as it is one of the three indicator variables adopted by the UN MDGs, specifically goal number 8 which is related to ICT diffusion. 
The economic group includes three economic variables. The Gross National Income (GNI) per capita in international purchasing power parity (ppp) dollars measures the income level of a country. The second variable in this group is the GINI index which measures the inequality of the income distribution. It takes on values between 0 and 1 , where 0 represents a situation where everyone has the same income and 1 represents a situation of high inequality. The last variable measures the importance of exports and imports of goods relative to the size of the economy. International trade enables technology diffusion, and it is expected that high levels of imports would enable ICT diffusion (Saggi 2002, Connolly 2003, Deichmann et al. 2007).

The third group also consists of three variables, and these reflect the level of infrastructure within a country. The variables in this group include the number of main telephone lines per 100 people in a population, the cost of a three minute landline phone call, and the level of electricity consumption per capita.

The fourth group includes demographic variables pertaining to age, education, etc. These variables are relevant to our study as age, gender, education, and other cultural traits have been found to be important to the digital discussion (Mendoza and Toledo 1997, Kubicek 2004, Deichmann et al. 2007). The specific variables in this group include the percentage of people between the ages of 15 and 64, the percentage of people aged 65 and older, primary and secondary school enrollments, and percentage of population that lives in urban areas.

For the risk group, we expand the work of Deichmann et al. (2007) and colleagues by using the country risk rating from IHS global insights rather than the Composite Risk Rating Index. The IHS country risk rating incorporates economic, political, legal, tax, operational, and security risk ratings while the composite risk rating only measures the economic and political risk. We believe the IHS risk rating presents a comprehensive picture of the quality of conditions and level of stability in each country.

In order to ensure readability of the graphs and adequately capture the change that has taken place in digital development, we chose to consider two time periods within the seven-year period for which we have data. We look at the beginning of the time period (2001) and the end of the time period (2007) for each country. Each country is labeled on the graph according to its three digit international code and time period, i.e. 1 (2001) and 2 (2007). Missing values in the dataset were handled through imputation using the multiple imputation models in PASW Statistics 17.

Multiple imputations generate possible values for missing values, thus creating several "complete" sets of data. For the purpose of our analysis we use the SPSS multiple imputation automatic method. The automatic method scans the data and determines the right method to use in generating possible values for missing values. The fully conditional specification and the monotone method are two methods that can be used under the automatic option. If the data shows a monotone pattern of missing values, the monotone method is chosen by the automatic method. The monotone method is a non-iterative method that can be used only when the data has a monotone pattern of missing values. A monotone pattern exists when you can order the variables such that, if a variable has a non-missing value, all preceding variables also have nonmissing values. For each variable in the monotone order, the monotone method fits a univariate (single dependent variable) model using all preceding variables in the model as predictors, then imputes missing values for the variable being fit. These imputed values are saved to the imputed dataset.

(C) Southern Regional Science Association 2014. 
If the data does not have a monotone pattern of missing values, the fully conditional specification is used. The fully conditional specification (FCS) is an iterative Markov chain Monte Carlo (MCMC) method that can be used when the pattern of missing data is arbitrary (monotone or non-monotone). For each iteration and for each variable in the order specified in the variable list, the fully conditional specification (FCS) method fits a univariate (single dependent variable) model using all other available variables in the model as predictors, then imputes missing values for the variable being fit. The method continues until the maximum number of iterations is reached, and the imputed values at the maximum iteration are saved to the imputed dataset. The FCS method uses the default number of 10 iterations for the automatic method.

Under the automatic method, the imputation model for each variable includes a constant term and main effects for predictor variables. The automatic method uses linear regression as the univariate model for scale variable, while logistic regression is used as the univariate model for categorical variables (see SPSS, 2007). We also applied constraints to prevent negative imputed values. Prior to the analysis, we standardize all variables in order to ensure that all variables enter the SOM algorithm with the same weight and that one variable does not dominate the computations above the others.

\section{ANALYSIS AND RESULTS}

The Kohonen map that was generated by the algorithm is presented in Figure 1. The Umatrix map consists of the 36 map positions and a hexagon between any two map positions. The color of this hexagon represents the Euclidean distance between the estimated vectors for the two bordering hexagons. Based on the scale, hexagons with darker red colors in our study represent greater distances (see Nguyen, Haughton and Hudson 2008). We are able to identify clusters or groupings of countries on the basis of the Euclidean distances between groups of countries as represented by the colored wall of hexagons which separate the groups, within which low distance hexagons appear. For example, the 2001 U-matrix in Figure 2 show a large cluster with blue hexagons in the lower map indicating the presence of many countries with similar estimated components in this part of the map while in the upper part of the map, we see much more heterogeneity and disparate behavior. The 2007 U-matrix on the right also shows a large number of countries in the lower map with blue hexagons indicating homogeneity while the upper map in 2007 indicates that the disparity we saw in the upper map in 2001 has now increased.

We utilize component maps (Figures 2 and 3) to better understand the position of each country on the U-matrix relative to each variable. Each variable is displayed along a color spectrum of blue to red, where the blue color indicates low estimated values and the red represents high values at the other end of the spectrum. Looking at the GNI map, we can interpret that as you move from the bottom of the U-matrix to the top, you increase in GNI. Countries at the top of the U-matrix such as Libya and South Africa have high GNI while countries at the bottom are low in GNI (Rwanda and Burundi). The opposite is the case for the risk variable. Countries at the bottom of the map are high risk countries while countries at the top are lower in risk. As you move from the bottom of the U-matrix to the top, the risk rating decreases.

The Kohonen map (Figure 1) indicates that Africa can be viewed as a group of similar countries in the lower part of the map while the upper map is made up of a heterogeneous group 
Figure 1: U-Matrices Showing Movement of Countries between 2001 and 2007
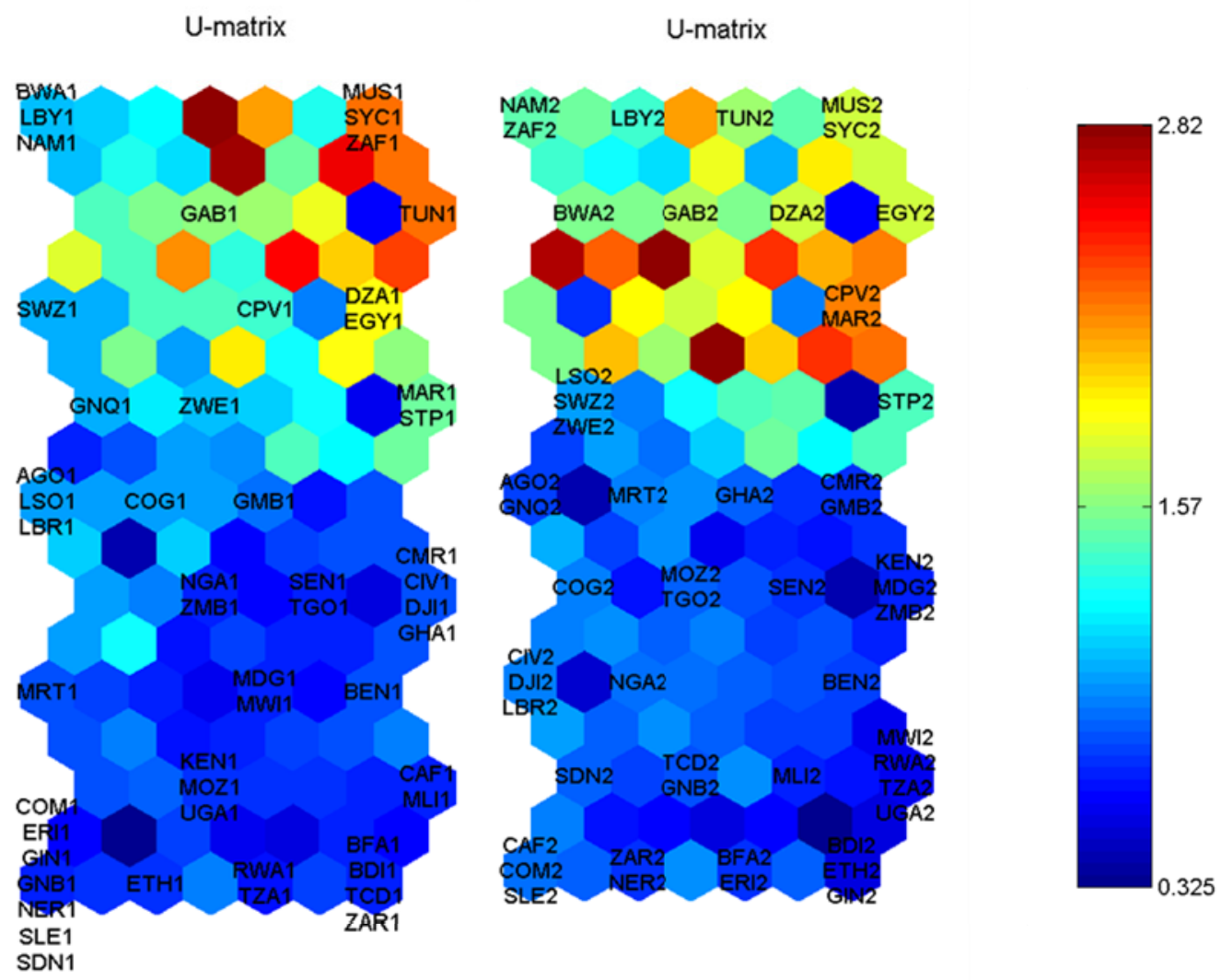

of countries along the five dimensions of digital development, economic development, infrastructure, demography, and risk. Most of the countries are positioned on the U-matrix alongside other countries from the same region. The Southern and Northern African countries are found in the heterogeneous part of the map at the top while the Western and Eastern African countries are found in a homogenous group at the bottom of the map with a distinct dark blue coloring. The component map (Figure 2 and 3) allows us to interpret the positioning of the countries on the U-matrix with respect to the five digital development, economic development, infrastructure, demography and risk. We see a vertical pattern where movement from the bottom to the top of the map indicates improvement in digital development, educational development, and lower risk profiles for both years (2001 and 2007). The countries in the top right corner of the 2001 map (Mauritius, Seychelles and South Africa) can be considered to be the countries high in digital development while the countries in the lower part appear to be the digitally stagnant countries. Interestingly, these countries in the top right corner also have a higher proportion of the population aged 15-64 and a higher proportion of the population aged 65 and above. This implies a higher life expectancy for these countries than other African countries. These countries also have high GNI per capita, high primary and secondary school enrollments and high electricity consumption. On the other hand, these countries have a low risk rating. Countries in the lower homogenous section of the Kohonen map show the highest risk rating of all African countries with red hexagons while showing low estimates of digital development, 
Figure 2: 2001 Component Maps: Digital, Economic, Infrastructure and Risk

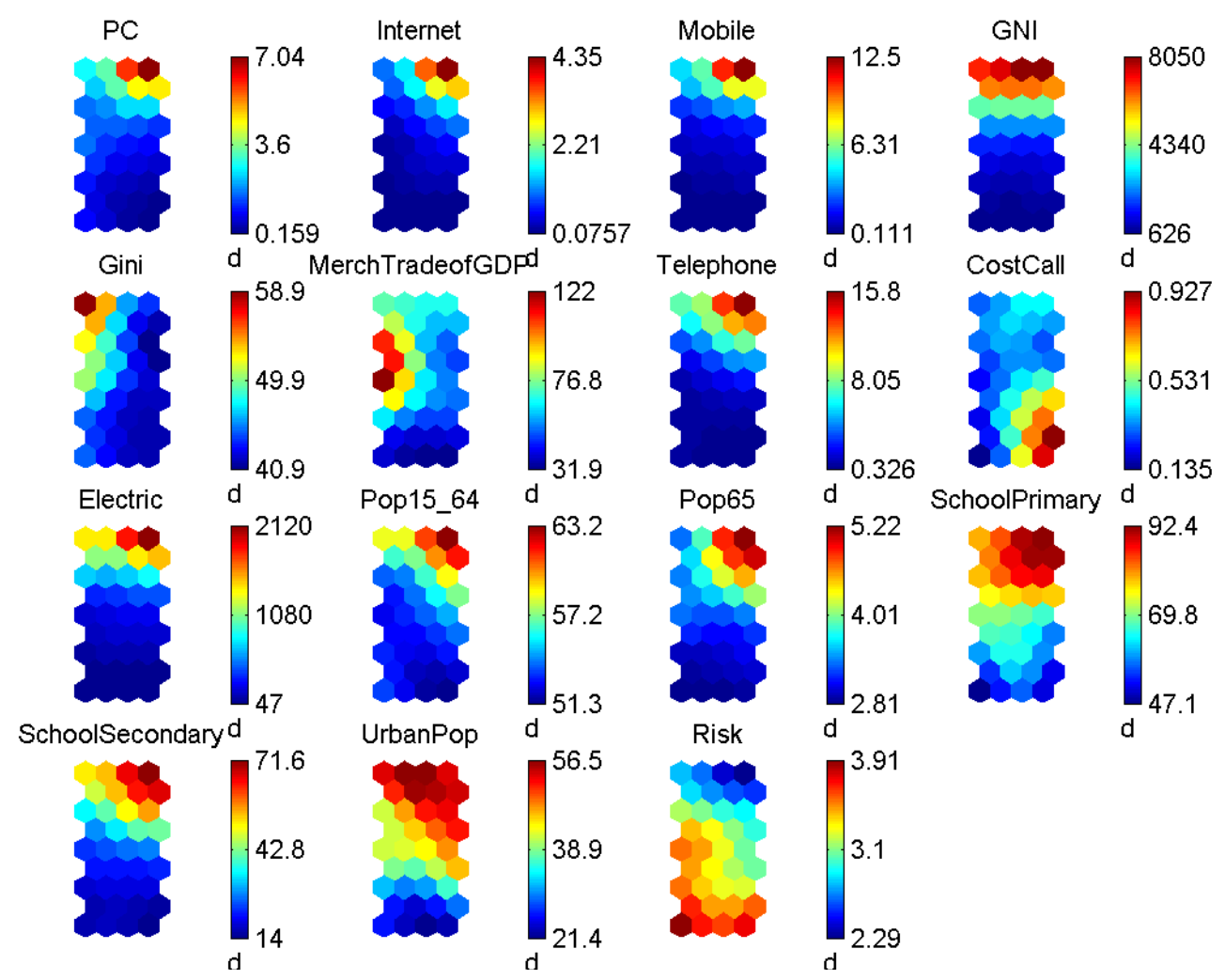

Figure 3: 2007 Component Maps

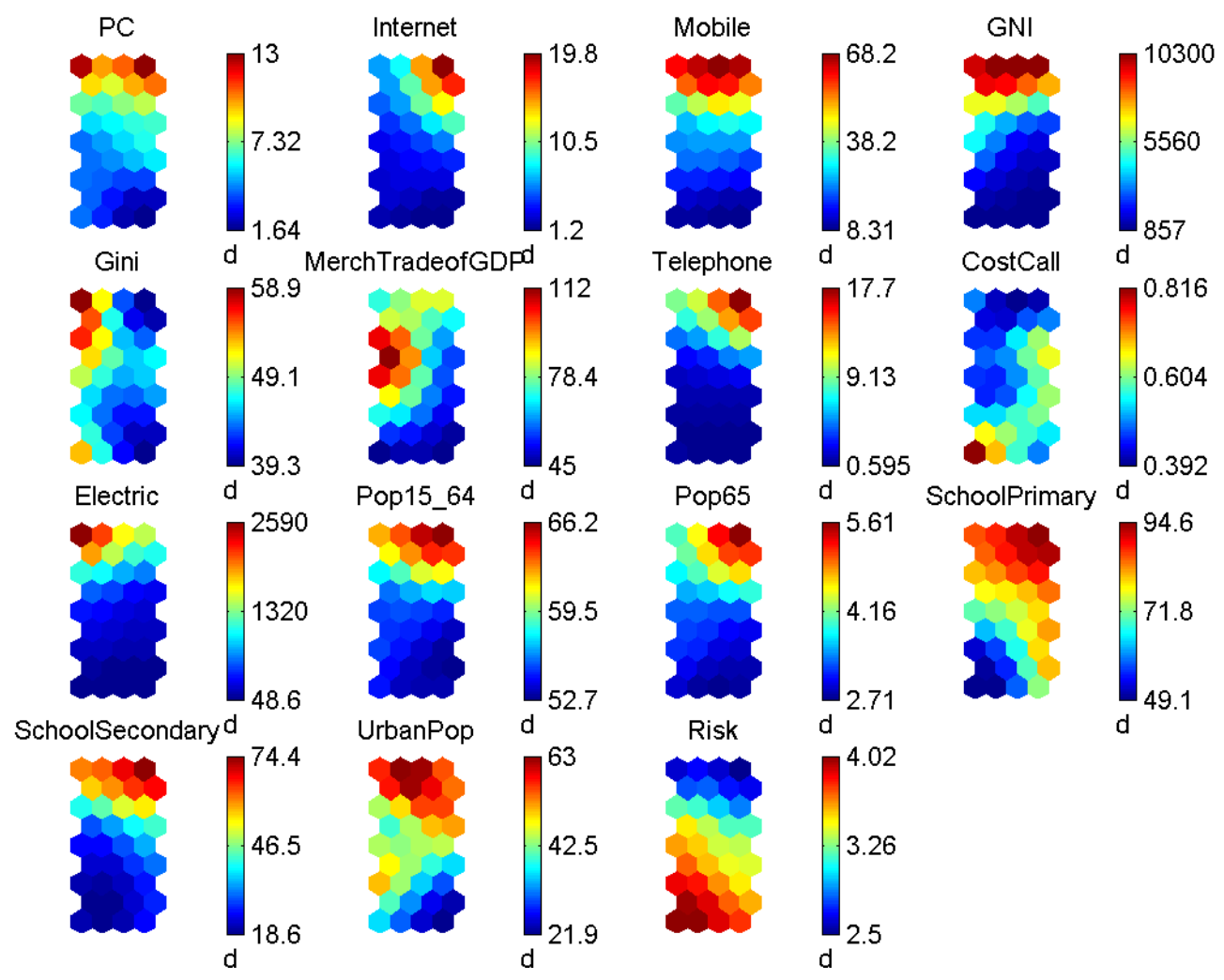

(C) Southern Regional Science Association 2014. 
economic, and education (blue hexagons). The countries in the bottom right corner of the map (Burkina Faso, Burundi, Chad and the Democratic Republic of Congo) have the highest cost of phone calls in Africa. Interestingly they are also the lowest in terms of digital development variables such as personal computers, Internet subscriptions, and mobile subscriptions. The majority of African countries are in the lower homogenous section of the map while there are only 12 countries in the upper part of the 2001 map. As noted earlier, we see more disparity in the upper part of the 2007 maps indicated by the greater number of red, yellow and green hexagons. By looking at the 2007 component map, we see some improvement in the personal computers and mobile phones adoption. Unlike in 2001, where only the countries in the top right corner had high estimates, we see that the countries in the top three rows now have high estimates as indicated by the red, yellow and green hexagons. On the other hand, we don't see much improvement with Internet access. Similar to the 2001 component map, only the top right corner of the map shows high estimates. This means that only Mauritius and Seychelles show consistently high estimates for Internet access in Africa, and Cape Verde and Morocco show slight improvements. In the $2001 \mathrm{U}$-matrix, the top right corner had red hexagons indicating that these countries (Mauritius, Seychelles and South Africa) though in the same position of the map were still separated by high distances i.e. still very different from each other. These distances are not as high as the top right corner of the $2007 \mathrm{U}$-matrix now has green hexagons, indicating that Mauritius and Seychelles are now more similar to each other in terms of digital development, economic development, infrastructure, demography and risk.

The top of the 2007 map represents the African countries with relatively high levels of ICT use, infrastructure, and low risk. We use the word "relative" here because these levels are relatively high compared to other African countries but might not be considered high when compared alongside countries from other developing regions. Countries at the top of the 2007 map describe these African countries. We consider the countries to be the growing countries.

These countries have shown some progress and development in the area of digital development and corresponding economic, infrastructure, and risk factors. Countries at the top of the 2007 map include Namibia, South Africa, Libya, Tunisia, Mauritius, Seychelles, Botswana, Gabon, Egypt, and Algeria. Countries in this cluster appear to have the lowest risk rating of all the African countries. Mauritius and Seychelles are two of the countries in this cluster, and the map indicates that they had high digital estimates in both 2001 and 2007.

It can be noticed from our analysis that the majority of countries either remained stagnant or showed insignificant progress in ICT development over the seven-year period. This could be attributed to a number of factors. For example, most of the countries had poor ratings when it comes to negotiating for debt facilities for foreign direct investments. The annual corruption index rankings published by Transparency International suggest that majority of African countries are classified among the most corrupt. Since the risk premium of investing in such environments is relatively higher, there is the likelihood that some potential investors may be discouraged from investing. Political risk is another possible explanation as many African countries are still grappling with the issue of democracy. Uncertainty and fear are always the antithesis of investment in general. When there is uncertainty about the stability of any government, it exacerbates fear in investors. There is also a large-scale lack of the basic infrastructure necessary for such investments to take place and foster progress at a reasonable rate.

(C) Southern Regional Science Association 2014. 
Countries that showed improvement from 2001 to 2007 include Botswana, Tunisia, Namibia, Cape Verde, Algeria, Egypt, Gabon and Morocco. These countries are high in digital development, educational development, and digital infrastructure while being very low in risk. Our result is consistent with prior studies which found that ICT development and educational development go hand in hand (Deichmann et al., 2007; Rasiah 2006). Also we see a distinct geographical divide in digital development on the map with West and East African countries in the bottom half of the map while North and South African countries cluster at the top. Northern and Southern African countries appear to be further along in their bid to lessen and ultimately eliminate the digital divide, specifically as it relates to cell phone access and use across regions.

The results of this study suggest that while the call of the UN MDGs is meant with good intentions, it is by no means sufficient to bring about conscious progress in ICT to African countries. Our results seem to be consistent with similar studies, which noted that African countries are still marred by a variety of socio-economic and political risks - corruption, unstable government, lack of transparency and good governance, insufficient infrastructure, poverty, and poor education and health, all of which hinder development in an economy.

\section{CONCLUSION}

In this study, we examine the patterns of ICT growth and development in Africa and also explored the existence of a digital disparity within the continent. The UN, for example, has been prominent in promoting its goal number 8 of the MDGs to achieve this objective. The significance of ICTs do not lie in the technologies themselves, but rather in the possibilities they open up for access to knowledge, information and communications. ICTs are elements of everincreasing importance as they affect the organizational processes of governments, businesses, non-governmental organizations (NGOs), institutions, and individuals on a daily basis. When ICTs are accessible at all levels, then development in other areas of the economy (infrastructure, healthcare, education, social services) can be enhanced.

This study provides one of the first longitudinal assessments of the UN's MDG goal 8 by applying Kohonen Self-Organizing Maps to explore the pattern of ICT growth and development, or lack thereof, in 48 African countries in tandem with economic and social measures. The results of our study show two cohorts of interesting findings. First, we identify patterns of digital development which occurred along with economic and infrastructural development. Second, there is a remarkable disparity within the African countries and this disparity increased over the years despite growth in ICT development. Further, our findings identified two main patterns in ICT growth in Africa. Eight countries showed improvement in ICT development in 2007 relative to the other African countries. Specifically, most of these countries are from Northern and Southern Africa and show relatively high levels of digital growth and infrastructure, with low risk, and higher life expectancies. On the other hand, the majority of the countries can be found in the bottom section of the Kohonen map. Most of these are West and East African countries. They show lower levels of ICT use and are higher risk countries. We found that countries tend to develop alongside other countries in the same region.

The outcome of this study presents some challenging thoughts to African countries going forward in the quest for development. We have identified that ICT development evolves in tandem with economic development, and that despite improvement in ICT growth within Africa, there is still a remarkable disparity among these countries. This leads us to conclude that we 
cannot consider ICT development alone in isolation from other measures but that true development requires a robust inclusion of digital, economic, and social development.

\section{REFERENCES}

Arribas-Bel, Daniel, Peter Nijkamp, and Henk Scholten. (2011) "Multidimensional urban sprawl in Europe: A self-organizing map approach," Computers, Environment and Urban Systems, 35, 263-275.

Asiedu, Elizabeth. (2006) "Foreign Direct Investment in Africa: The Role of Natural Resources, Market Size, Government Policy, Institutions and Political Instability," World Economy, 29, 63-77.

Bessler, David. (2003) “On World Poverty: Its Causes and Effects' Food and Agricultural Organization (FAO) of the United Nations," Research Bulletin, Rome.

Chen, Wenhong and Barry Wellman. (2007) "The Global Digital Divide-Within and Between Countries," IT and Society, 7, 39-45.

Chinn, Menzie D. and Robert W. Fairlie. (2007) "The Determinants of the Global Digital Divide: A Cross-Country Analysis of Computer and Internet Penetration," Oxford Economic Papers, 59, 16-48.

Connolly, Michelle. (2003) "The Dual Nature of Trade: Measuring Its Impact on Imitation and Growth," Journal of Development Economics, 72, 31-55.

Deichmann, Joel I., Abdolreza Eshghi, Dominique Haughton, Michele Masnghetti, Selin Sayek, and Heikki Topi. (2006) "Exploring Break-Points and Interaction Effects among Predictors of the International Digital Divide: An Analytical Approach," Journal of Global Information Technology Management, 9, 47-71.

Deichmann, Joel, Abdolreza Eshghi, Dominique Haughton, Michele Masnghetti, Selin Sayek, and Sam Woolford. (2007) "Measuring the International Digital Divide: An Application of Kohonen Self-Organizing Maps," Journal of International Knowledge and Learning, $3,552-575$.

Giddens, Anthony. (2000) Runaway World: How Globalization Is Reshaping our World. Routledge, New York.

Ho, Chin-Chang and Shu-Fen Tseng. (2006) "From Digital Divide to Digital Inequality: The Global Perspective," International Journal of Internet and Enterprise Management, 4, 215-227.

Hua, Guangying, Maria Skaletsky, and Kimberly Westermann. (2009) "Exploratory Analysis of CIA Factbook Data Using Kohonen Self-Organizing Maps,” CS-BIGS, 3, 48-59.

IHS Global Insight Country Risk Ratings. www.Ihsglobalinsight.com

Industry Statistics. (2008) "Operator Data on Active Telephone Subscribers in Nigeria," http://www.ncc.gov.ng/subscriberdata.htm.

International Telecommunication Union, http://www.itu.int/home/index.html.

Jensen, Mike. (2002) "ICT in Africa - A Status Report," available online in January 2014 at http://www.weforum.org/pdf/Global_Competitiveness_Reports/Reports/GITR_2002_2003/ICT_Africa.pdf.

(C) Southern Regional Science Association 2014. 
Kauko, Tom. (2004) “A Comparative Perspective on Urban Spatial Housing Market Structure: Some More Evidence of Local Sub-markets Based on a Neural Network Classification of Amsterdam," Urban Studies, 41, 2555-2579.

Kaski, Samuel, and Teuvo Kohonen. (1995) "Structures of Welfare and Poverty in the World Discovered By the Self-Organizing Map," Laboratory of Computer and Information Science, available in January 2014 at http://citeseerx.ist.psu.edu/viewdoc/download?doi=10.1.1.53.3954\&rep=rep1\&type=pdf.

Kim, Jinwoo, Inseong Lee, Yeonsoo Lee, and Boreum Choi. (2004) "Exploring e-business Implications of the Mobile Internet: A Cross-National Survey in Hong Kong, Japan Korea," International Journal of Mobile Communication, 2, 1-21.

Kohonen, Teuvo. (2001) Self-Organizing Maps, $3^{\text {rd }}$ ed. Springer Verlag: Berlin.

Kubicek, Paul. (2004) "Organized Labor in Post-Communist States: Will the Western Sun Set on It, Too?" Comparative Politics, 32, 83-102.

Kulkarni, Rajendra, Laurie A. Schintler, Roger R. Stough, and Kenneth Button. (2002) "A Kohonen Self-Organizing Map Approach to Modeling Growth Pole Dynamics," Networks and Spatial Economics, 2, 175-189.

Kumar, Sameer and Christopher Zahn. (2003) "Mobile Communications: Evolution and on Business Operations," Technovation, 23, 515-520.

LaFraniere, Sharon. (2005) "Cellphones Catapult Rural Africa to $21^{\text {st }}$ Century," New York Times, August 25.

Larose, Daniel T. (2005) Discovering Knowledge in Data: An Introduction to Data Mining. John Wiley \& Sons, Inc.: Hoboken, N.J.

Mazrui, Ali, and Ala Mazrui. (2001) "The Digital Revolution and the New Reformation," Harvard International Review, 23 (Spring), 52-55.

Mendoza, Miguel Rafael H., and Jose A. Alvarez de Toledo. (1997) "Demographics and Behavior of the Chilean Internet Population," Journal of Computer-Mediated Communication, 3, article 10, available on line in January 2014 at http://onlinelibrary.wiley.com/doi/10.1111/j.1083-6101.1997.tb00068.x/full.

Nguyen, Phong, Dominique Haughton, and Irene Hudson. (2008) "Living Standards of Vietnamese Provinces: a Kohonen map," Case Studies in Business, Industry and Government Statistics 2, 109-113.

Oyelaran-Oyeyinka, Banji and Catherine Nyaki Adeya. (2004) "Internet access in Africa: Empirical Evidence from Kenya and Nigeria," Telematics and Informatics. 21, 67-81.

Rao, Madanmohan. (2001) "How Real Is the Internet Market in Developing Nations?" OnTheInternet, Available online in January 2014 at https://www.isoc.org/oti/articles/0401/rao.html.

Rasiah, Rajah. (2006) "Information and Communication Technology and GDP per Capita," International Journal of Internet and Enterprise Management. 4, $202-214$.

Roycroft, Trevor R. and Siriwan Anantho. (2003) "Internet Subscription in Africa: Policy for a Dual Digital Divide," Telecommunications Policy, 27, 61-74. 
Sachs, Jeffrey D. (2007) "The Importance of Investment Promotion in the Poorest Countries," World Investment Prospects to 2010: Boom or Backlash? Report the Economist Intelligence Unit and the Columbia Program on International Investment, New York, pp. 78-81. [This publication can be viewed by subscribing online at www.store.eiu.com.]

Saggi, Kamal. (2002) “Trade, Foreign Direct Investment, and International Technology Transfer: A Survey," World Bank Research Observer, 17, 19-235.

SOM Toolbox 2.0 Documentation. (2003) [http://www.cis.hut.fi/somtoolbox/documentation/]

SPSS Inc. (2007) PASW Missing Values 18. A manual available online in January 2014 at http://www.unt.edu/rss/class/Jon/SPSS_SC/Manuals/v18/PASW\%20Missing\%20Values\%2018.pdf.

Tyler, Zachary C. and Sucharita Gopal. (2010) "Sub-Saharan Africa at a Crossroads: A Quantitative Analysis of Regional Development," Pardee Papers Series, No.10, Boston University, May.

United Nations Department of Economic and Social Affairs. (2008) United Nations Millennium Development Goals Report, 2008. Last accessed in January 2014 at http://www.un.org/millenniumgoals/2008highlevel/pdf/newsroom $/ \mathrm{mdg} \% 20 \mathrm{reports} / \mathrm{MDG}$ Report_2008_ENGLISH.pdf.

Vesanto, Juha, Johan Himberg, Esa Alhoniemi, Juha Parhankangas. (2000) SOM Toolbox for Matlab 5, Technical Report A57. Finland: Helsinki University of Technology, April. Available online in January 2014 at http://www.cis.hut.fi/somtoolbox/package/papers/techrep.pdf.

World Bank. World Bank Development Indicators. (2007) Available on line in January 2014 at http://data.worldbank.org/data-catalog/world-development-indicators.

Yan, Jun and Jean-Claude Thill. (2009) "Visual Data Mining in Spatial Interaction Analysis with Self-Organizing Maps," Environment and Planning B, Planning and Design, 36, 466486.

(C) Southern Regional Science Association 2014. 